\title{
MOCK-UP DE HABITAÇÃO: RELAÇÃO ENTRE CONCEPÇÃO, DESENVOLVIMENTO E EXECUÇÃO NO ENSINO DE PROJETO1
}

\author{
HOUSING MOCK-UP: RELATIONSHIP BETWEEN DESIGN, DEVELOPMENT AND \\ EXECUTION IN BUILDING DESIGN EDUCATION
}

\author{
Maria Isabel Imbronito ${ }^{1}$ \\ Universidade São Judas Tadeu, São Paulo, SP, Brasil, imbronito@gmail.com \\ Eneida de Almeida ${ }^{2}$ \\ Universidade São Judas Tadeu, São Paulo, SP, Brasil, eneida.almeida@uol.com.br
}

\begin{abstract}
Resumo
O presente artigo constitui o relato de uma experiência didática exercitada no presente momento, que permite estabelecer uma reflexão sobre o ensino de projeto e os fundamentos teóricos próprios do campo disciplinar da arquitetura. Trata-se de um exercício proposto na disciplina Introdução ao Projeto de Arquitetura e Urbanismo, aplicado a alunos do primeiro ano de projeto do curso de Arquitetura e Urbanismo da Universidade São Judas Tadeu. O exercício é composto por diferentes etapas, que são descritas e têm os objetivos apresentados no decorrer do artigo. A última etapa, correspondente à construção dos mock-ups em escala 1:1, possibilita a execução de um elemento complexo e a experiência de ocupar e perceber o espaço construído. Ao visar uma construção real, tanto do ponto de vista da organização do espaço como do domínio técnico-construtivo, o exercício de projeto de arquitetura dá ênfase às implicações, para a aprendizagem do aluno, do enfrentamento de aspectos construtivos em sincronia com a própria concepção do espaço. O interesse é assinalar que a atividade de construção do mock-up oferece ao processo de projeto elementos materiais concretos para a manipulação simultânea de múltiplas prerrogativas do projeto, propiciando a experimentação e verificação in loco da complexidade do sistema estrutural em suas propriedades físicas, especialmente nas relações entre o dimensionamento (e modulação) das peças, a estabilidade do conjunto e a própria forma. As considerações feitas procuram estabelecer parâmetros para o desenvolvimento futuro de uma pesquisa no ensino de Projeto de Arquitetura no que tange à relação entre a matéria e o espaço, bem como o aperfeiçoamento constante do sistema construtivo utilizado.
\end{abstract}

Palavras-chave: Ensino de Projeto de Arquitetura. Habitação experimental. Tectônica da madeira.

\begin{abstract}
This paper reports an educational experience, which allows a reflection on design education and the theoretical foundations in Architecture's disciplinary field. It concerns an exercise, applied to first year undergraduate students in Architecture and Urbanism at São Judas Tadeu University, in São Paulo. The exercise consists on different steps, which are described and have their objectives presented on the course of the article. The last step corresponds to the construction of 1:1 mock-ups, which allows the students to build of a complex architectonic element and to observe the space. Since the exercise aims a real construction in both aspects, the organization of space and the technical and constructive domain, the article emphasizes the implications for the student's learning process by facing constructive aspects while designing the space. It is presumed that the mock-up building activity provides concrete material elements for the simultaneous handling of multiple prerogatives of the project, enabling experimentation and spot verification of the complexity of the structural system in its physical properties, especially in relation to scale - and modulation - of the component parts, the stability of the assembly and the shape itself. The considerations seek to establish parameters for the future development of research in teaching architecture design in regard to the relationship between matter and space, as well as the constant improvement of the construction system used to build the mock-ups.
\end{abstract}

Keywords: Building Design education. Experimental housing. Tectonic timber.

\section{How to cite this article:}

IMBRONITO, Maria Isabel; ALMEIDA, Eneida de. Mock-up de habitação: relação entre concepção, desenvolvimento e execução no ensino de projeto. PARC Pesquisa em Arquitetura e Construção, Campinas, SP, v. 6, n. 4, p. 291-303, dez. 2015. ISSN 1980-6809. Disponível em: <http://periodicos.sbu.unicamp.br/ojs/index.php/parc/article/view/8641675>. Acesso em: 19 mar. 2016. doi:http://dx.doi.org/10.20396/parc.v6i4.8641675. 


\section{Introdução}

No primeiro ano do curso de Arquitetura e Urbanismo da Universidade São Judas Tadeu, na disciplina de Introdução ao Projeto de Arquitetura e Urbanismo, equipes de alunos executam mock-ups de habitações mínimas por eles projetadas. Trata-se de um exercício cuja origem remonta à fundação do Curso de Arquitetura, e que foi inicialmente concebido pelos professores Antonio Gil de Andrade, Kátia Azevedo Teixeira, Luiz Augusto Contier e Shieh Shueh Yau. Ao longo dos anos, o exercício recebeu contribuição de diversos professores até chegar a sua conformação atual.

A principal particularidade do exercício é, sem dúvida, a materialização em escala 1:1 das unidades propostas pelos alunos, com toda a complexidade envolvida na construção em madeira e a possibilidade de experimentar o espaço em escala real. Entretanto, é importante ressaltar que o exercício contempla diferentes etapas com objetivos distintos. Sendo assim, a validade do exercício está na sua completude, mais do que no resultado evidente que é o mock-up construído.

Pretende-se, através deste artigo, apresentar o exercício e discutir seus resultados, e estabelecer uma reflexão sobre a proposta de enfrentamento de questões inerentes à materialidade e à construção, concomitantemente à concepção do próprio espaço, por parte de alunos ingressantes no curso de Arquitetura. Devido à complexidade estrutural do modelo construído em escala 1:1, o exercício proposto, além de exigir a formulação espacial e sua representação, estabelece um vínculo consistente entre o espaço e o sistema construtivo, o que reforça as ações de projeto dentro do campo disciplinar da arquitetura, e insere a ambos, projeto e obra, no processo de aprendizagem. O sistema construtivo empregado e as grandes dimensões transformam o modelo em escala 1:1 em objeto-fim do processo de projeto, em vez de percebêlo como mero meio de representação de algo ainda por construir. Deste modo, o mock-up se caracteriza como uma experiência espacial e construtiva completa, a ser enfrentada utilizando-se um sistema construtivo determinado. Do ponto de vista pedagógico, o modelo não é apenas utilizado como ferramenta de projeto. Através dele, é também possível desenvolver e experimentar o sistema construtivo, estabelecer a relação entre espaço e matéria, e ainda perceber, sob os aspectos visual, tátil e espacial, o efeito do espaço em sua real dimensão.

Ao relato da experiência didática, agrega-se a discussão a respeito do ensino de projeto de arquitetura e dos fundamentos teóricos do campo da arquitetura inseparáveis da prática: uma teoria da arquitetura como fundamento do fazer.

\section{Procedimentos metodológicos}

O exercício apresentado neste artigo consiste na problematização de questões específicas de programa e construção, a serem solucionadas na forma de projetos arquitetônicos que consideram tanto a concepção como a execução, utilizando-se de procedimentos práticos de projeto e obra.

A partir da problematização, experimentação e registro sistemáticos, configura-se na prática pedagógica um laboratório experimental do espaço e da construção, cuja produção é alimentada por discussões conceituais e espaciais, problemas construtivos e pelo resultado prático dos exercícios.

A aplicação contínua do exercício, ano a ano, e o aperfeiçoamento das questões espaciais e do sistema estrutural, caracterizam o desenvolvimento do exercício como uma investigação na qual as soluções são experimentadas e permanentemente aprimoradas, e cujo resultado será transmitido às turmas seguintes. Este modo de investigação leva ao aperfeiçoamento contínuo, o que possibilita comparar soluções e avançar no processo reflexivo, no processo construtivo e no processo pedagógico. Para isso, o procedimento que subsidia o exercício considera a ação conjunta de alunos e professores, e alia a prática do ateliê de projeto com a execução em oficina. Neste trabalho conjunto, cabe aos alunos experimentar soluções de projeto de arquitetura, desenvolver e construir os modelos, tendo produzido, ao longo do tempo, um conjunto significativo de obras (cerca de 70 mock-ups erguidos apenas nos últimos quatro anos). Por sua vez, cabe aos professores apresentar os problemas a serem enfrentados e as referências iniciais, transmitir a experiência acumulada e facilitar o entendimento tectônico aos alunos, necessário às etapas de projeto e construção.

A formulação dos modelos arquitetônicos, entendidos enquanto construção de hipóteses para determinado problema, e a verificação das soluções propostas, são procedimentos práticos usuais da atividade de projeto de arquitetura enquanto prática-reflexiva. Esta prática, na execução dos mock-ups aqui relatados, está estendida à construção de um elemento material complexo em escala real, o que amplia os elementos disponíveis para a verificação da validade das propostas apresentadas para além do campo abstrato do projeto.

Para reforçar a importância da continuidade do exercício, cabe mencionar a relação que o exercício propicia entre pesquisa e docência, entre pesquisa e projeto, e também entre pesquisa e aprendizagem. Ao abordar este exercício como uma pesquisa em projeto, esta contribui para o aprimoramento docente, na medida em que incita à experimentação de novas soluções e propicia uma reflexão 
cumulativa a ser aplicada ao exercício. O estudante, por sua vez, ao tomar parte em um exercício completo, tem a oportunidade de estabelecer o vínculo entre prática e teoria, bem como entre o projeto e a obra. Pode-se mencionar o ganho no aprendizado dado pela autonomia decisória das equipes de alunos desde a concepção até a execução, atrelada a uma verificação in loco dos problemas e soluções apresentados, seja com relação ao desempenho do material, seja com relação ao dimensionamento do espaço e resultado final.

Por fim, com base na experiência propiciada pela sequência de atividades previstas na disciplina (em sala de aula, na prática do canteiro e na percepção do espaço), é possível estabelecer, no âmbito desse artigo, uma reflexão sobre o impacto do enfrentamento de um exercício com tal complexidade por parte de alunos ingressantes no curso de Arquitetura e Urbanismo.

\section{Justificativa para abordagem do ensino de projeto a partir da relação entre a matéria e o espaço}

A arquitetura contemporânea reflete a ampliação das prerrogativas e condicionantes que interferem no projeto de arquitetura para além do campo disciplinar. Este processo é entendido como uma qualidade, no sentido de ampliar o contato da arquitetura com outras áreas de conhecimento. Contudo, por vezes pode ter o efeito de valorizar aspectos que são alheios, e desvalorizar o projeto arquitetônico enquanto enfrentamento dos problemas do espaço e da construção. Simultaneamente, a arquitetura é entendida como uma área de conhecimento que oferece possibilidades de pesquisa e procedimentos que são sistêmicos e interdisciplinares por natureza, que se mostram alinhadas ao campo epistemológico contemporâneo, o que faz crescer, junto às demais áreas, o interesse em compreender os procedimentos dinâmicos da ação em projeto frente aos problemas da atualidade. Assim, de modo contrário à busca por critérios alheios ao campo disciplinar por parte dos arquitetos, é a arquitetura que tem atraído atenção de outras áreas para seus procedimentos de ação.

Nota-se, contudo, dentro do campo da arquitetura, uma inclinação da produção prática e teórica recente em direção a uma retomada de aspectos inerentes ao projeto, de modo a fortalecer o campo disciplinar, além de correntes que propõem o estudo de procedimentos de determinados arquitetos, extraindo interpretações da obra arquitetônica que vinculam o resultado do projeto ao próprio ato de conceber, como ação movida por valores que antecedem $\mathrm{o}$ projeto $\mathrm{e}$ que se submete às particularidades de cada obra específica. Destas correntes teóricas, destacamos três contribuições capazes de fornecer subsídio para o exercício de projeto descrito neste artigo.

A primeira fundamentação que embasa a experiência de ensino do projeto de arquitetura aqui narrado é o texto de Vittorio Gregotti, Contro la fine dell'architettura (2008), no qual o autor manifesta o interesse e a urgência em se refletir a respeito dos limites do campo disciplinar da arquitetura na contemporaneidade.

Interessa retomar a discussão proposta por Gregotti acerca do significado do termo teoria para a arquitetura, quando comparado ao adotado pela ciência ou pela filosofia, na medida em que, no campo disciplinar da arquitetura, esta não constitui "nem construção em si autônoma, nem hipóteses de explicação progressiva do mundo", mas a conjunção simultânea de "fundamento, escolha e instrumento do agir concreto não diferenciável do seu êxito" (GREGOTTI, 2008, p. 6 - o grifo é nosso).

$\mathrm{O}$ autor enfatiza que os projetos de pesquisa do campo das artes e da arquitetura são elaborados com base em hipóteses cuja intencionalidade se manifesta a partir de uma verdade limitada e específica, não generalizável, como uma espécie de "metáfora de uma totalidade fundada sobre uma ética da convicção e da necessidade" (Id. p, 7). Adverte Gregotti que a teoria, ao menos para a arquitetura, exatamente pelo fato de coincidir com o fundamento do fazer, não é história, estética ou crítica; que, ao contrário, têm o papel de transferir a ação projetual do mundo concreto da práxis ao do juízo interpretativo e referir-se ao objeto arquitetônico conjuntamente à sua elaboração.

Um segundo autor apresenta uma abordagem da tectônica que se mostra útil, compreendendo a potencialidade de expressão vinculada à técnica sob a ação do arquiteto. Ao apontar para a importância de "como a arquitetura é realizada, para além da manifestação formal", com o intuito de "elevar o caráter (da arquitetura) através de sua precisa realização", Kenneth Frampton, em Studies on Tectonic Culture (1995), retoma a relação primordial da ação de transformar o material para a realização da obra arquitetônica.

O terceiro autor é Helio Píñon que, no ensaio Teoria do Projeto (2006), faz, como Gregotti, a arguição pela teoria da arquitetura como o estudo dos procedimentos de projeto, considerando, por sua vez, ênfase no aspecto material da arquitetura. Ao discorrer sobre a relação entre forma e matéria, Pínon observa a dificuldade de se contornar os limites estabelecidos pela compartimentação dos conteúdos disciplinares como, por exemplo, a separação das disciplinas referentes aos sistemas construtivos daquelas ligadas ao ensino do projeto de arquitetura. $\mathrm{O}$ autor sustenta que a atividade da arquitetura é inseparável da materialidade, isto é, não há como concebê-la restrita exclusivamente ao "limbo evanescente 
das ideias". Segundo o autor, a prática do projeto não pode ser confundida com a expressão gráfica de um desejo, ou com o delinear traços a partir de uma ilusão. Pelo contrário, ela necessariamente se associa ao empenho em "conceber artefatos materiais, habitáveis (...) dotados de uma consistência formal que, na medida em que a contém, transcende a componente utilitária (...)." (PIÑON, 2006, p. 122). Para Piñon,

a construção é um instrumento para conceber, não uma técnica para resolver: não deve determinar solução alguma, senão propiciar decisões cujo sentido necessariamente há de transcendê-la; seu destino é contribuir decisivamente para a sistematicidade congênita do edifício. A construção é a condição da arquitetura e a tectonicidade um valor inequívoco dos seus produtos: qualquer edifício melhora substancialmente ao atender aos aspectos construtivos que foram previstos para a sua realização; isso não significa, naturalmente, aplicar mecanicamente soluções construtivas elaboradas sem propósito nem objetivos confessáveis. (...) A atenção à construção é uma condição básica do ato de conceber. (2006, p. 126).

A aproximação entre as contribuições de Gregotti e de Piñon permite admitir que, no âmbito disciplinar da arquitetura, a teoria seja inseparável da prática, ou melhor, corresponda ao próprio modo de ser do projeto, a um conjunto de possibilidades que se estabelecem no domínio da intencionalidade do próprio projeto, em consonância com as necessidades programáticas e com o contexto específico em que se insere. Por outro lado, articular as reflexões de Piñon e de Frampton fortalece a compreensão de que concepção e construção, quando enfrentadas simultaneamente, podem contribuir para melhor adequação, conveniência e coerência entre os elementos que compõem o objeto projetado.

\section{Etapas do exercício de projeto}

O exercício completo desenvolvido pelos alunos de primeiro ano da Universidade São Judas Tadeu tem, entre outros objetivos, o de estabelecer a relação entre o espaço e a matéria que o delimita. O exercício compreende fases distintas, através das quais ocorre um contínuo desenvolvimento e aprofundamento do trabalho, com o enfrentamento de problemas que mudam a cada etapa. São elas:

- Projeto arquitetônico de uma habitação mínima contida num espaço de $4 \times 4 \times 4 \mathrm{~m}$, que comporta os usos de estar, comer, cozinhar, dormir e banhar-se. Tratase de uma etapa de trabalho individual, com apresentação de estudo preliminar, com desenhos e maquete em escala 1:20 (figura 1).

- Escolha dos projetos a serem executados em tamanho real. Etapa de discussão coletiva que busca selecionar, entre todos os projetos apresentados, aqueles que serão executados, a partir de critérios apresentados e debatidos entre alunos e professores desde o início da apresentação do exercício.

- Desenvolvimento dos projetos a serem executados. Etapa de detalhamento dos projetos que serão construídos pelas equipes, que compreende desenhos gerais (plantas, cortes e elevações), desenhos específicos da estrutura, a maquete do espaço e uma maquete estrutural elaborada na escala 1:10 ou 1:20.

- Construção de modelo na escala 1:1. Etapa de canteiro, na qual os estudantes elaboram os modelos das habitações em escala real, a partir do projeto executivo desenhado pela equipe.

- Conclusão do exercício. Etapa de encerramento do exercício, caracterizada pela discussão sobre o espaço construído, a percepção e apropriação deste espaço, e por uma reflexão sobre as diversas fases do processo de trabalho.

\section{Etapa de projeto: espaço para morar}

O exercício tem início com a proposta de projetar individualmente uma habitação que atenda às atividades de estar, dormir, comer, cozinhar e lavar-se, nas dimensões de um cubo de $4 \mathrm{~m}$ de lado.

Devido às restrições dimensionais e à proposta de revisão dos conceitos da casa tradicional, as questões determinadas pelo enunciado do exercício são distintas daquelas usualmente presentes no programa doméstico como, por exemplo, a especialização dos compartimentos da casa ou sua relação com o sítio. O habitáculo que se propõe é caracterizado por um espaço único, que atenda integralmente às necessidades para se morar. Entenda-se, deste modo, que o espaço não pode ser subdividido para configurar recintos estanques e, ainda assim, deve ter cada uso devidamente caracterizado. Cada porção de espaço deve ser desenhada, portanto, a partir da relação com o uso (atividades e equipamentos necessários) e com o corpo (dimensões em planta e em altura).

Além disso, segue-se a orientação de não ocupar o espaço com mobiliário no sentido de "decorar" o ambiente. É requisito básico conformar o espaço com o mesmo material e sistema construtivo do próprio invólucro da casa, de modo a definir planos com profundidades e alturas convenientes para os usos de sentar, deitar, trabalhar sobre bancada, etc. Essas superfícies devem estabelecer ainda relação com as aberturas e com a conformação espacial do próprio volume.

A principal condição para a ocupação do espaço é a utilização de um mezanino, cujo acesso obedece à seguinte regra: 
- Pé direito mínimo de 2,20 m nas áreas em que seja necessário circular e permanecer em pé; desta forma, não é permitido propor um mezanino à cota intermediária de $2 \mathrm{~m}$, o que torna o acesso interditado nos dois pavimentos.

- Com o pé direito mínimo estabelecido de 2,20m para uma pessoa em pé, o espaço resultante no pavimento alternado, com $1,75 \mathrm{~m}$ de altura (descontados $5 \mathrm{~cm}$ da espessura do plano horizontal) deverá ser ocupado por algum equipamento como mesa, bancada ou armário, ou por planos cujo uso seja feito na posição sentada ou deitada, como assentos ou cama.

- Em função destas regras, o desenho dos dois pavimentos (térreo e mezanino) se inter-relacionam, tanto em planta como verticalmente, e o projeto deverá prever soluções de encaixe dos usos e equipamentos de modo a permitir acesso a todos os espaços propostos, respeitadas as restrições de altura relacionadas aos usos.

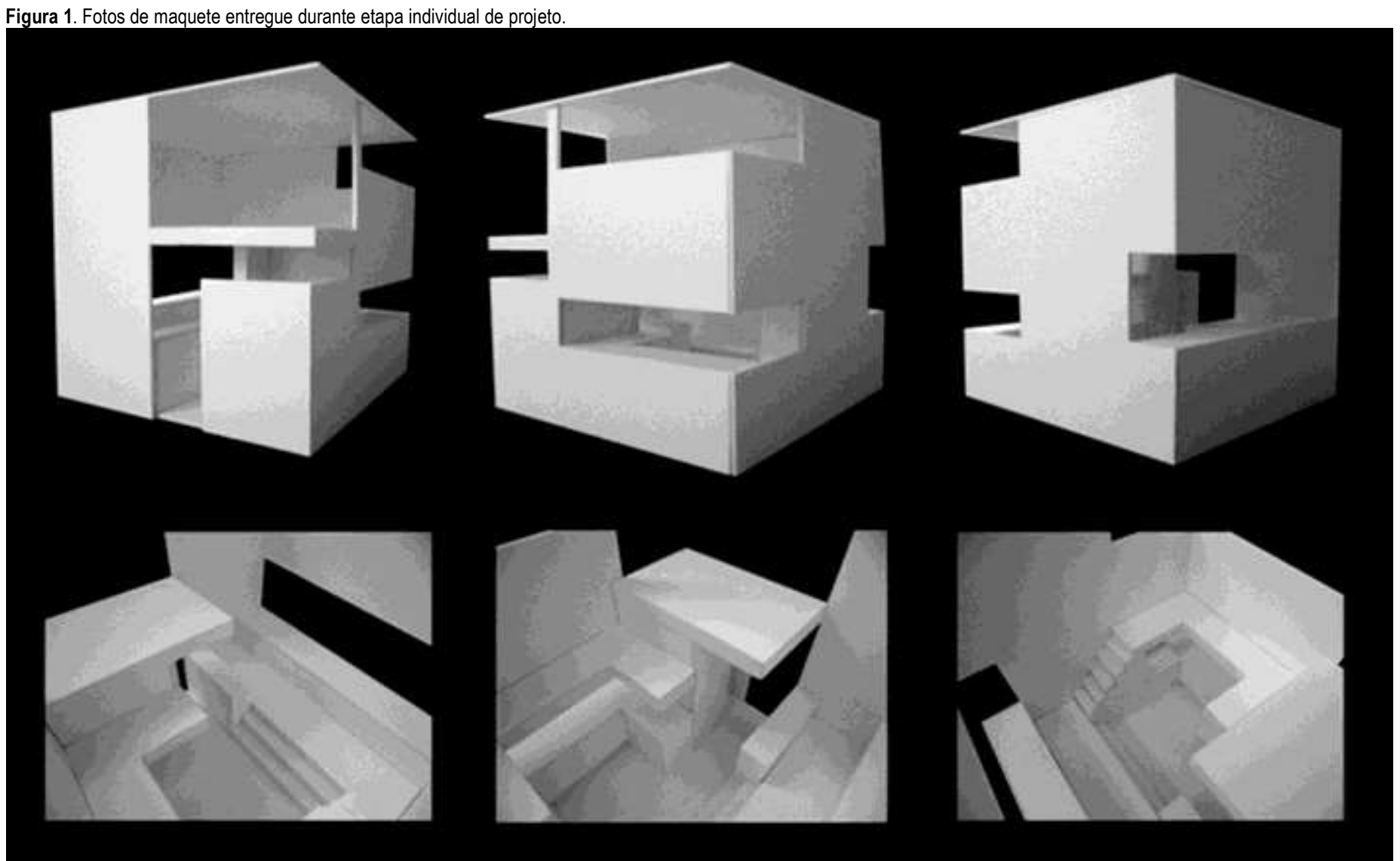

Fonte: Projeto e fotos do aluno Bruno Alves Manso, 2013.

\section{Etapa de escolha dos projetos para execução}

A partir das entregas dos projetos individuais, tem início uma etapa de discussão para escolha dos projetos que serão executados. Todos os modelos reduzidos são reunidos e é convocado um foro coletivo.

É importante, neste momento, a retomada dos critérios iniciais apresentados durante a etapa de projeto, evidenciando aos estudantes os aspectos importantes a serem considerados para a seleção dos trabalhos. Estes critérios, além de insistir nas premissas de projeto colocadas inicialmente e exigir o atendimento às prerrogativas presentes no enunciado do exercício, compreendem:
- a capacidade de solução conjunta dos problemas da forma e do programa;

- o correto dimensionamento dos espaços, tendo em vista o usuário (ergonomia);

- a possibilidade de apropriação de plataformas e níveis para usos diversos;

- o estabelecimento de percursos e relações visuais através do espaço;

- a integridade do desenho e a qualidade do espaço arquitetônico, a partir da relação entre o invólucro (cheio) e o espaço (vazio).

É fundamental que todos os alunos se apropriem dos critérios para análise dos projetos e se envolvam na 
escolha dos trabalhos, de modo a promover uma discussão comparativa e qualitativa das soluções, e garantir a adesão dos alunos aos projetos escolhidos para o desenvolvimento das etapas seguintes.

Os projetos passam então por uma etapa de revisão e detalhamento.

Etapa de detalhamento dos projetos
Ao final da etapa individual de trabalho, escolhem-se três projetos por turma para serem detalhados e executados. Os projetos são desenvolvidos em equipe, até a etapa de projeto executivo (figura 2), e acompanhados por uma maquete estrutural (figura 3). Para tanto, é necessário aprofundar o entendimento do sistema tectônico empregado na execução do mock-up.

Figura 2. Prancha de detalhamento do projeto, elaborada em equipe.
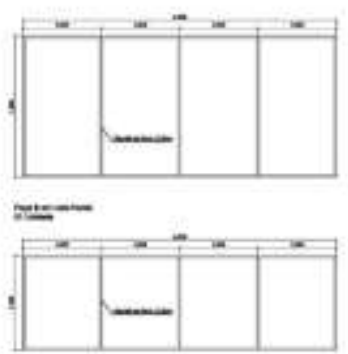

mise-m

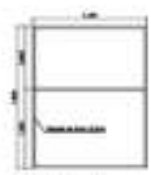

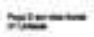

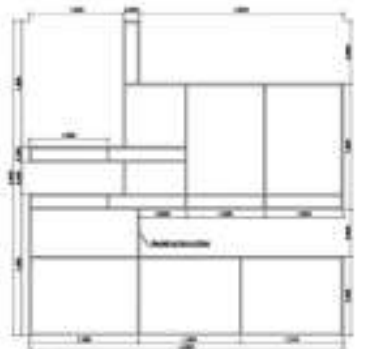

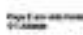

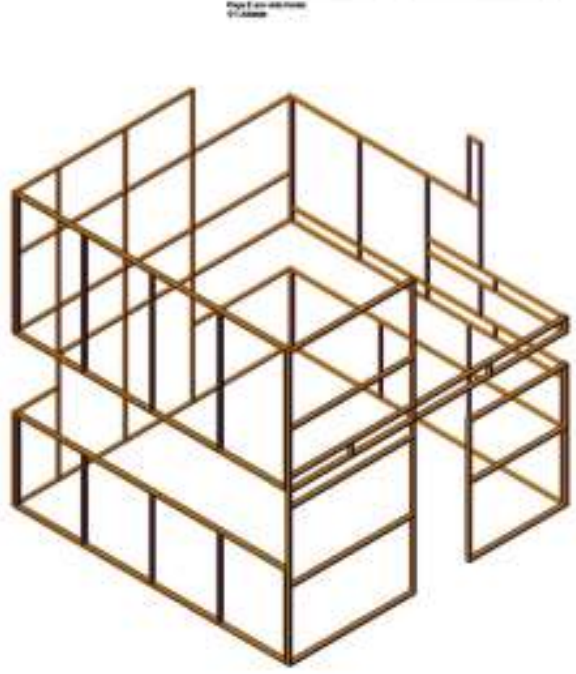

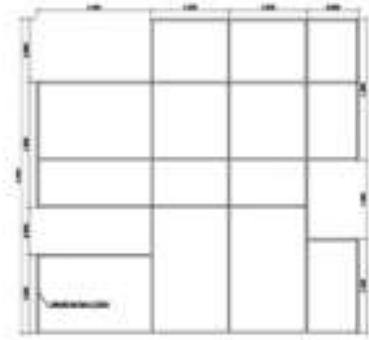

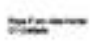

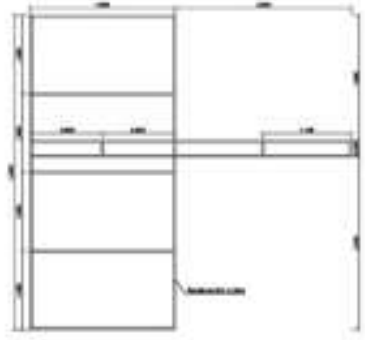

프-
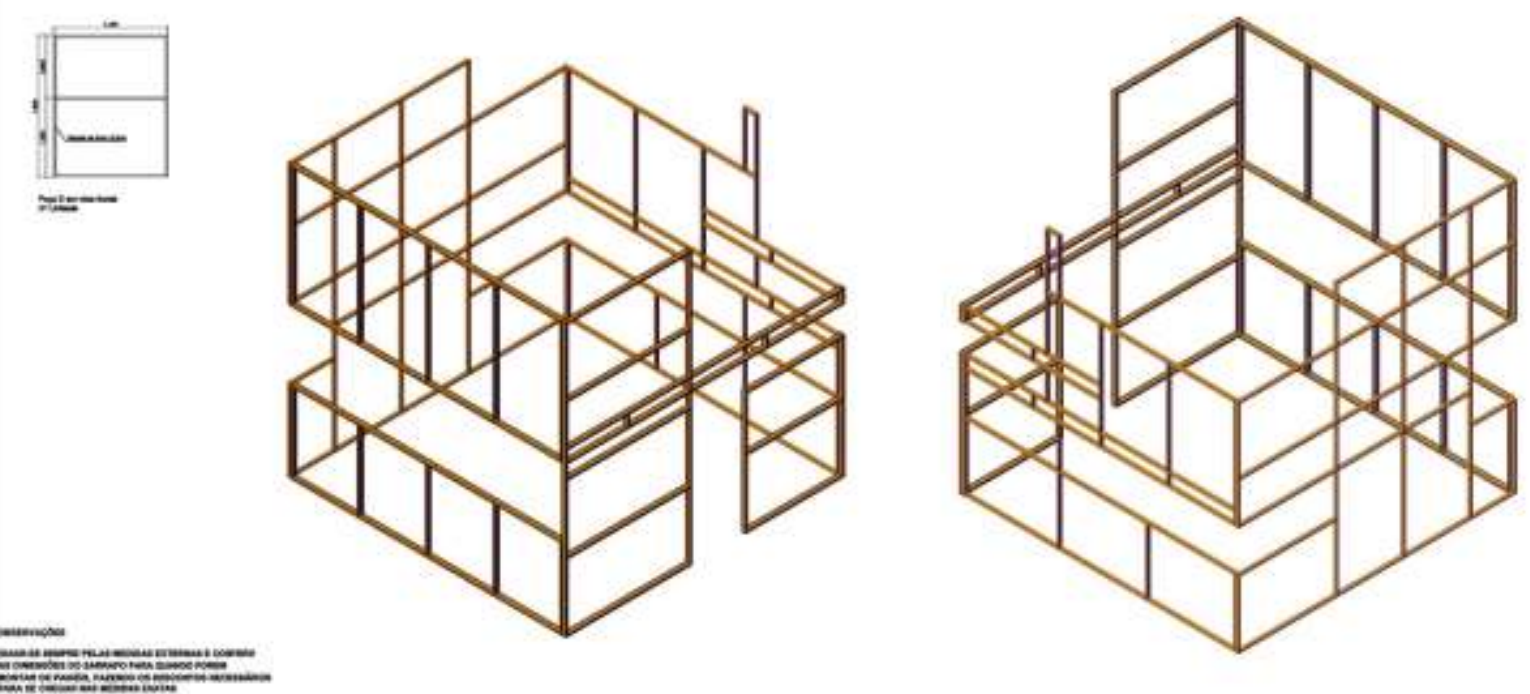

Fonte: Projeto original do aluno Bruno Alves Manso desenvolvido pela equipe.

Figura 3. Fotos de maquete estrutural dos painéis perimetrais, elaborada em equipe. Projeto original do aluno Bruno Alves Manso, 2013.

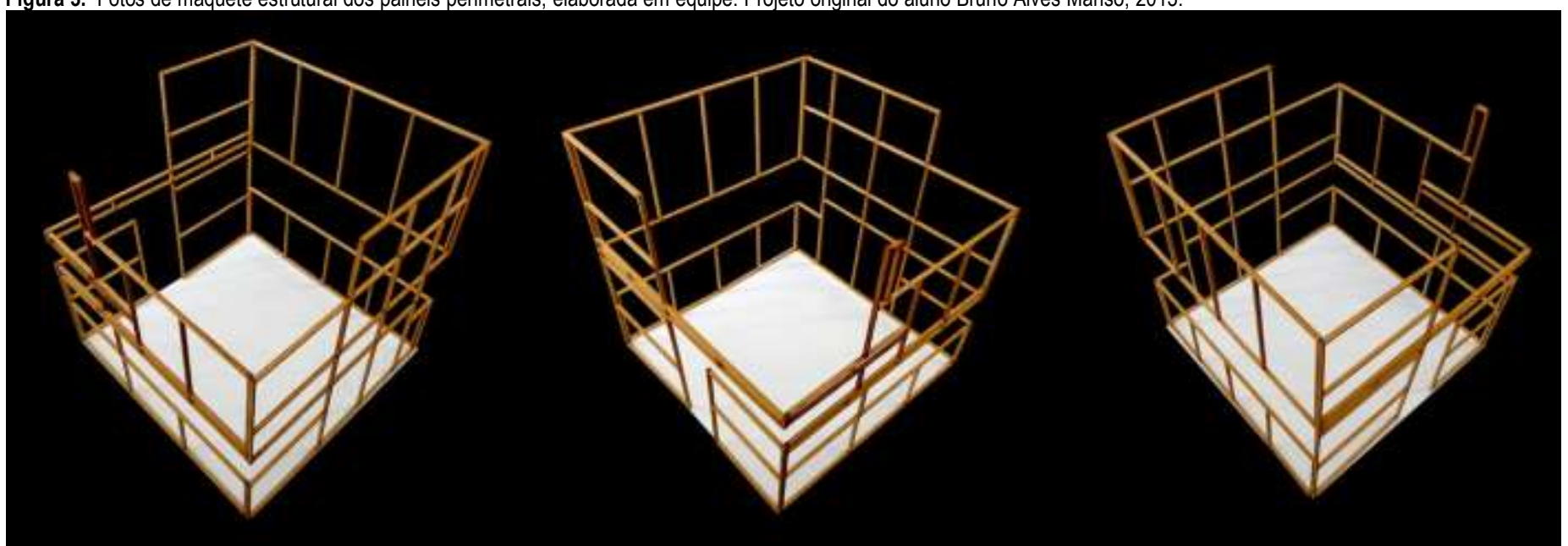

Fonte: Foto dos autores. 


\section{A tectônica da madeira}

O sistema construtivo utilizado na execução do mock-up é leve, entendido em oposição à construção maciça, conforme conceito empregado por Deplazes e Wieser, apoiando-se nas teorias de Gottfried Semper. Segundo os autores, uma construção com base nesta tectônica

\section{é formada por uma estrutura articulada de elementos leves, um entretecido de elementos lineares em forma de barra, que se encaixam para configurar uma trama plana ou tridimensional. Disto resulta uma retícula espacial, preenchida com elementos construtivos que cumprem a função de divisão. A armação portante não cria por si um espaço arquitetônico; este somente surge no passo seguinte, quando a trama espacial é fechada ou, segundo Gottfried Semper, revestida. (...) As aberturas adaptadas ao sistema são como vazios (ocos) estruturais, cuja dimensão está subordinada à divisão por partes da trama estrutural. (DEPLAZES, 2010, p.14, tradução nossa).}

A estrutura em barras associadas, ao utilizar pouco material, é incapaz de garantir vedação, estanqueidade ou isolamento térmico e acústico, e precisa ser complementada por outros componentes que cumpram a função de fechamento e garantam o limite físico do espaço arquitetônico. Tradicionalmente, no sistema tectônico com base na madeira, o elemento de fechamento é efêmero, como tecido, palha ou papel. Por conta desta característica, nos sistemas tectônicos leves ocorre certa interdependência entre o material de fechamento e a estrutura, o que determina uma vocação para constituir sistemas construtivos complexos com subsistemas secos acrescidos à estrutura principal.

O sistema tectônico leve adotado para a construção do mock-up utiliza montantes compostos por sarrafos de madeira de seção $5 \times 2 \mathrm{~cm}$, aparafusados de modo a compor painéis.

Os painéis de madeira que compõem o mock-up são montados no chão (figura 4) e revestidos pelo lado externo com placas de papelão grampeado aos montantes, recebendo nas juntas acabamento com fita gomada (figura 5). A dimensão restrita do papelão, com largura máxima de $1 \mathrm{~m}$, exige a presença regular dos montantes, que passam a configurar quadros rígidos. A leveza dos painéis já montados permite que sejam manuseados e erguidos.

Além de cumprir primordialmente o papel de montantes, nos quais é fixado o fechamento em papelão, a paginação dos sarrafos nos requadros obedece a critérios internos ao projeto, servindo de estrutura para plataformas, bancadas, passarelas e vãos.

A combinação dos painéis entre si, por sua vez, deve prever a continuidade estrutural das peças. $\mathrm{O}$ desenho da paginação dos quadros de madeira requer, portanto, além de rigor e precisão, o entendimento tridimensional da estrutura a ser construída, determinando os alinhamentos dos perfis e o travamento do sistema como um todo.

A paginação do sistema tectônico utilizado, uma vez concluído o mock-up, torna-se visível, no lado externo, pelas juntas do papelão e, internamente, através da posição dos montantes, estabelecendo uma relação visual intrínseca entre o espaço e a materialidade que o constitui. Esta relação é reforçada pela marcação das superfícies constituintes do volume, cuja medida corresponde, em múltiplos, às próprias dimensões dos planos que delimitam o espaço, e determinam os recortes e as aberturas.

Essa evidência confirma aos alunos a necessidade de precisão na ordenação do espaço e a importância de um traçado que regula a própria constituição do elemento arquitetônico, caracterizando o detalhamento do projeto como um exercício de relação entre o volume, a superfície e a estrutura.

Figura 4. Painéis de madeira executados independentemente e empilhados sobre 0 piso. Projeto de Matheus Lima Santos e equipe, 2015.

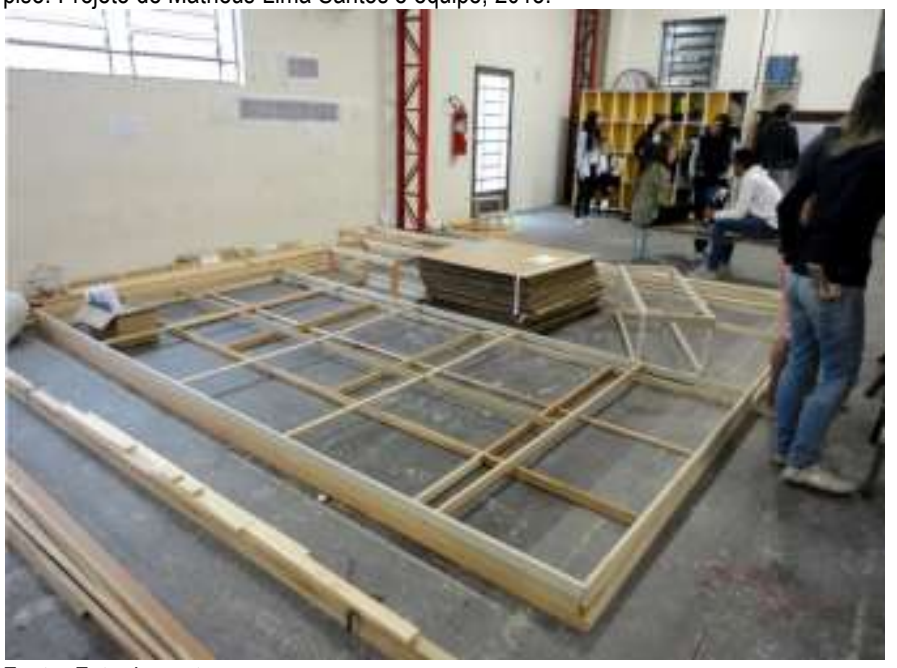

Fonte: Foto dos autores.

Figura 5. Painéis de madeira revestidos com papelão e empilhados sobre o piso, aguardando montagem.

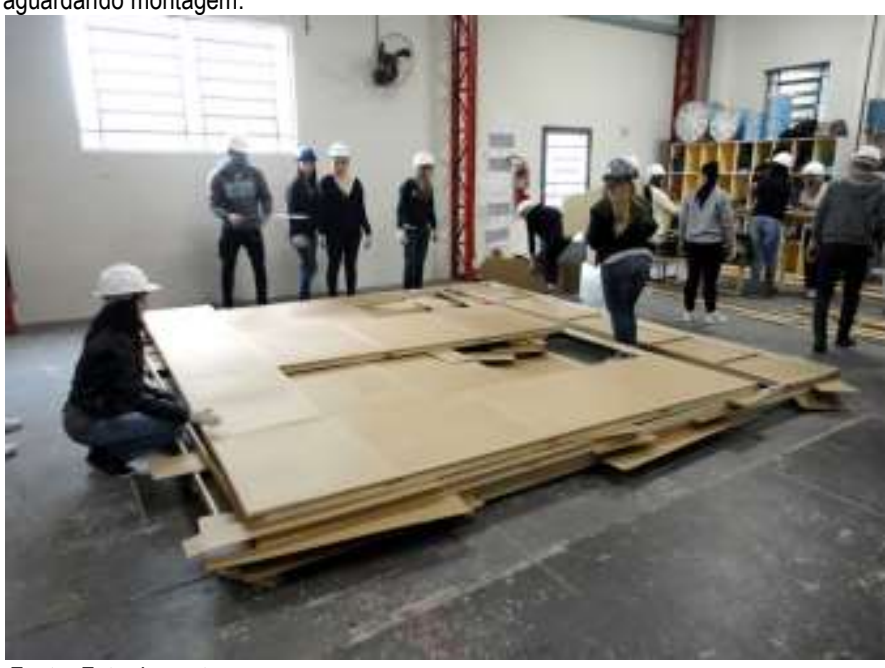

Fonte: Foto dos autores. 


\section{Etapa de construção}

Depois de revestidos e acabados, os painéis são erguidos, manobrados e fixados uns aos outros com parafuso (figuras 6, 7 e 8). Como cada painel é independente, ocorre a duplicação dos montantes nas quinas correspondentes à junção dos painéis. Nessa junção, o painel poderá estar disposto por fora, sobreposto ao painel contíguo de modo a arrematar a quina do volume, ou por dentro, ficando compreendido entre painéis opostos.

A posição relativa dos quatro painéis perimetrais deve ser definida na etapa de projeto e obedecida criteriosamente na montagem, pois é determinante tanto para se atribuírem as dimensões das peças como para garantir o desempenho da estrutura. A melhor condição para arranjo dos quatro painéis é específica para cada mock-up, e dependerá do comportamento da estrutura como um todo.

A determinação da sequência de montagem e as estratégias para a execução do mock-up são parte constituinte do exercício. O planejamento da produção das peças e da sequência de montagem é feito conjuntamente com o raciocínio estrutural. Os painéis e travamentos necessários para o equilíbrio do mock-up precisam estar prontos para serem utilizados no momento da montagem, e esta deve ser concluída de uma única vez, pois não é permitido interromper a montagem do mock-up sem que este esteja completamente estruturado. Depois de erguida a estrutura principal, outros elementos e volumes internos podem ser finalizados em etapas posteriores, como as escadas, bancadas, alguns volumes superiores, etc.

Durante o processo de montagem, peças auxiliares podem ser utilizadas para conferir sustentação provisória, bem como garantir o esquadro e permitir o travamento da estrutura. Contudo, ao final da montagem, o conjunto deverá permanecer estável após a remoção das escoras auxiliares provisórias utilizadas durante o processo de montagem.

Com o tempo, as estruturas dos mock-ups tem se desenvolvido no sentido de transferir a ênfase dos apoios perimetrais para estruturas espaciais mais complexas, com travamentos entre painéis feitos por elementos transversais internos ao espaço, estruturas penduradas ou elevadas, e pequenos volumes internos estruturados independentemente e suportando planos horizontais. Esta abordagem contribui para enriquecer a pesquisa espacial relacionada à pesquisa estrutural, permitindo dissolver o volume cúbico inicial e conformar volumetrias internas, dobras do invólucro para dentro do espaço, volumes suspensos, etc.
Figura 6. Montagem de um mock-up, com alunos dispondo os painéis na posição correta para fixação definitiva. Projeto de Matheus Lima Santos e equipe, 2015.

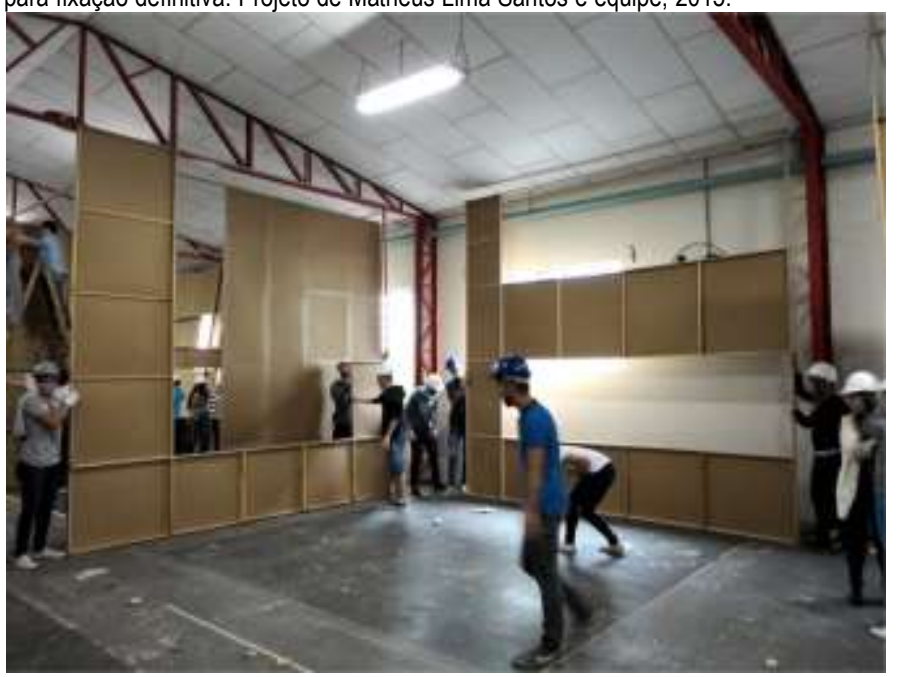

Fonte: Foto dos autores.

Figura 7. Sequência de imagens da montagem do mesmo mock-up. Manobrando e fixando os painéis.

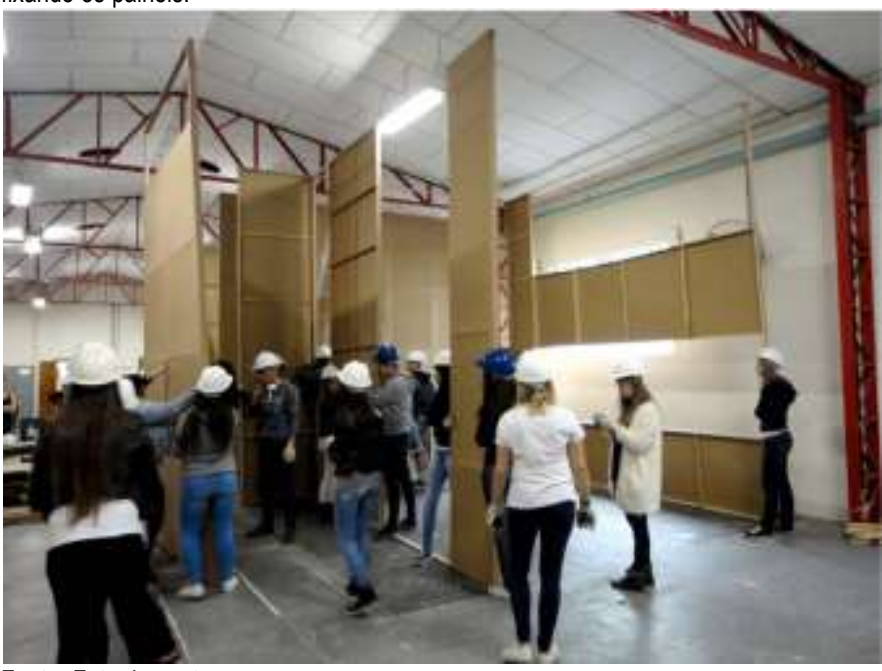

Fonte: Foto dos autores.

Figura 8. Sequência de imagens da montagem do mesmo mock-up. Manobrando e fixando os painéis.

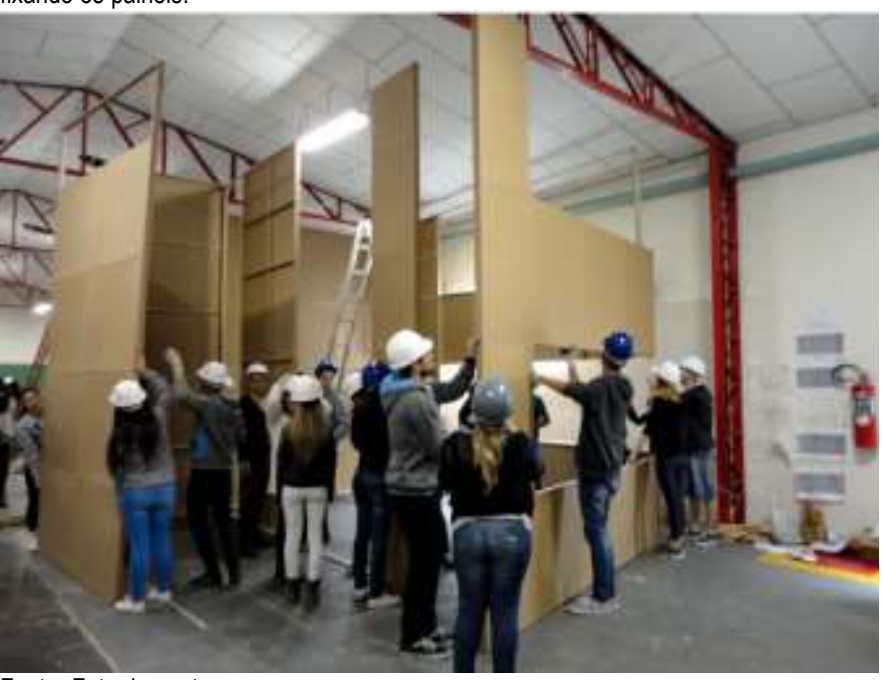

Fonte: Foto dos autores. 


\section{Etapa final: a experiência do espaço e a discussão sobre o processo de trabalho}

Com o mock-up finalizado, é possível experimentar o espaço das habitações e estabelecer com os alunos uma discussão que aborda vários aspectos, desde o início do exercício. É possível retroceder a cada etapa de desenvolvimento do projeto, desde o estudo preliminar, passando pela escolha do projeto, detalhamento, execução e verificação do espaço, de modo a ressaltar a importância de cada fase (o conceito do projeto, o detalhamento, a verificação do projeto, o controle da obra, o rigor de execução, etc.).

As trocas de experiência entre as equipes de alunos são incentivadas, de modo a abordar discussões sobre:

- as questões iniciais do projeto, relacionadas ao uso do espaço e à relação com a forma, com possibilidade de aferir, in loco, o funcionamento dos espaços, a adequação das medidas ao usuário e relações espaciais e visuais internas e externas. Nesse momento, é possível intervir e simular o uso da habitação, verificando seu desempenho em termos de ergonomia (figura 9);

- a coerência entre a conceituação e o espaço, a partir das soluções dadas por cada um dos mock-ups. A ideia é ressaltar a lógica interna a cada solução, e compreender a qualidade das propostas a partir da pertinência das decisões tomadas em projeto;

- as relações entre o espaço interno e externo, o papel das aberturas e a diluição do volume;

- a relação entre a construção e o espaço. Com o mockup construído, é possível perceber, através dos alinhamentos dos montantes e das juntas do papelão, a importância da modulação para estruturar volumes e aberturas no sistema tectônico leve. $\mathrm{O}$ fato de o detalhamento e a execução serem feitos pelos próprios alunos confirma e reforça a atenção necessária ao rigor do sistema construtivo.

\section{Considerações sobre os resultados e apontamentos para a continuidade do exercício enquanto pesquisa}

De que é feita a coisa da arquitetura? De matérias organizadas tendo em vista uma certa forma: a forma do habitar; é, portanto, a forma das matérias ordenadas com a finalidade de habitar. Podemos definir tal ordenação como a estrutura da operação projetual que, por seu lado, não consiste em nenhuma das operações isoladas através das quais construímos a obra, mas é capaz de conferir significado a cada uma destas operações, de dar-lhes forma, o que precisamente, para nós, é a forma arquitetônica de nosso encontro com o mundo. (GREGOTTI, 2004, p.27)

O exercício proposto, desde o projeto, passando pela a construção até a percepção do espaço real, contempla simultaneamente dois aspectos presentes no ensino de projeto de arquitetura: o aspecto programático-espacial e o aspecto construtivo.

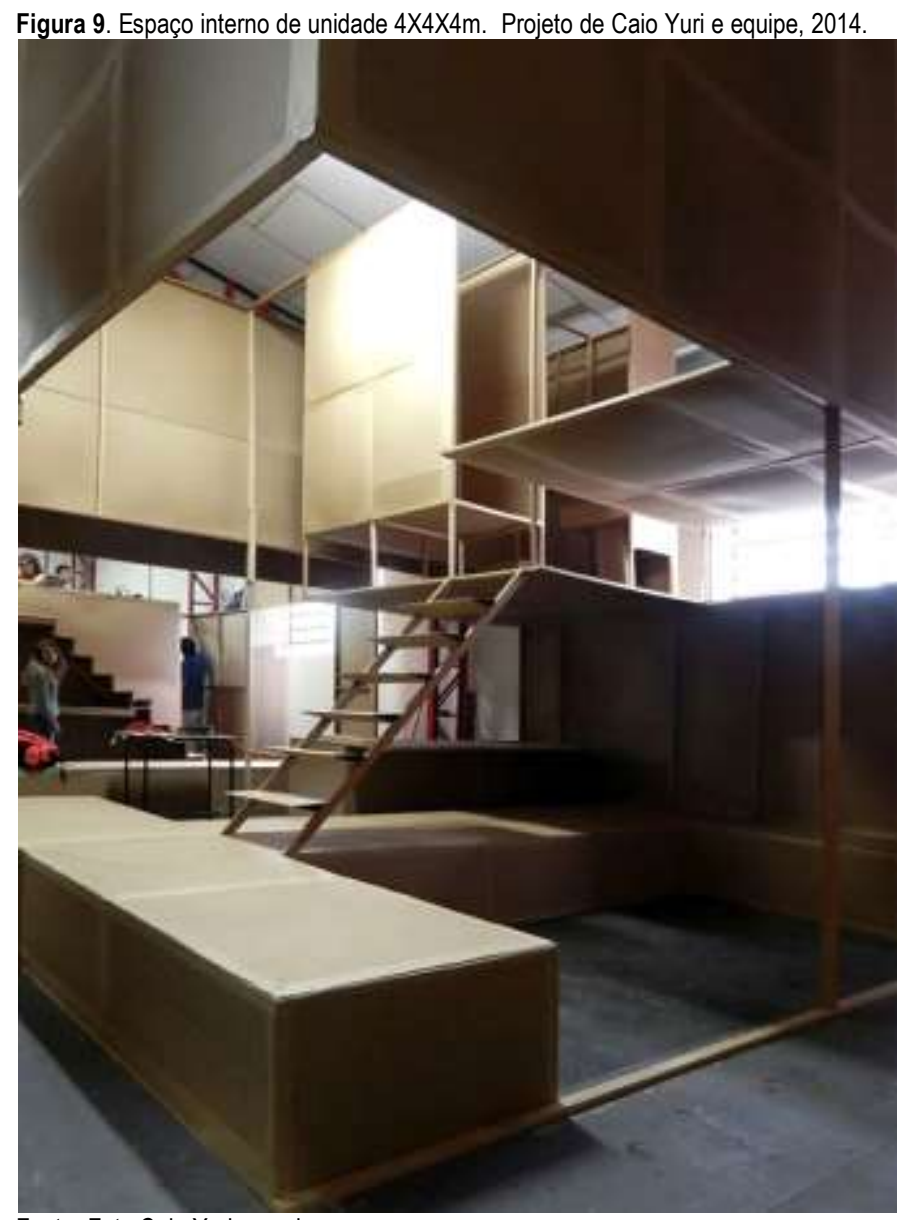

Fonte: Foto Caio Yuri e equipe.

Neste sentido, recorre-se novamente a Kenneth Frampton que, na introdução de Studies on Tectonic Culture, no texto Reflexions on the Scope of the Tectonic, reconstitui o pensamento teórico para a introdução e consideração do espaço no pensamento arquitetônico a partir do século XX. O autor não pretende menosprezar a "primazia" do espaço na arquitetura moderna e contemporânea, mas, conforme sua colocação,
...mediar e enriquecer a prioridade dada ao espaço, através de uma reconsideração dos modos construtivos e estruturais pelos quais, por necessidade, o espaço é realizado. Desnecessário dizer que não estou aludindo à mera revelação da técnica construtiva, mas a seu potencial expressivo (FRAMPTON, 1995, p.2, tradução nossa).

No exercício de projeto apresentado, aliada à discussão sobre o uso da casa, os hábitos de morar, as dimensões dos espaços e dos equipamentos, introduz-se a questão 
construtiva de modo indissociado ao próprio projeto do espaço. Essa característica do exercício alimenta uma reflexão sobre a linguagem e expressão da arquitetura, oriunda tanto do espaço como da técnica.

Com relação ao aspecto programático-espacial, a especificidade do programa proposto, juntamente com as dimensões reduzidas e a participação do invólucro, estendido às superfícies horizontais e verticais internas, determinam um caráter experimental aos projetos. Isto leva a uma investigação do espaço doméstico que desmonta, por assim dizer, o repertório de soluções trazido pelo aluno, para reconstruir os critérios com base nas dimensões do corpo, na ergonomia e nas possibilidades de uso dinâmico e flexível do espaço da casa.

A conformação espacial, contudo, está diretamente relacionada à estrutura composta por montantes e paginação da superfície que delimita o espaço. O espaço abre-se, dobra-se e dinamiza-se em decorrência da disposição do invólucro, e este é mediado pela estrutura tectônica em madeira que o constitui. Desta maneira, a concepção tectônica e a concepção do espaço estão interligadas.

Com relação ao aspecto construtivo, além da relação entre o espaço e a matéria, há ainda um ponto a ser observados: o enfrentamento de questões estruturais reais.

A construção do mock-up, que utiliza um sistema tectônico leve com montantes compostos por sarrafo de madeira e fechamento em placas de papelão, faz a transposição de um exercício cuja etapa inicial corresponde a um estudo preliminar de exploração espacial, para um exercício de detalhamento e organização da construção. Deste modo, os problemas a serem enfrentados ganham um potencial de experimentação real, o que orienta a tomada de decisões em projeto a partir de critérios concretos.

Os mock-ups apresentam uma complexidade estrutural importante, não sendo por nós entendidos como simples maquetes. Por mais que a técnica e materiais utilizados não sejam aplicáveis a situações reais, a lógica presente na concepção da estrutura do mock-up constitui um exercício lógico completo que apresenta rebatimento direto para outras técnicas construtivas existentes a serem enfrentadas futuramente pelo aluno.

O sistema construtivo de madeira revestida com papelão, desenvolvido no mock-up, representa a simulação da organização do raciocínio em projeto que vincula estrutura, modulação e espaço. $\mathrm{O}$ raciocínio de projeto, uma vez aprendido, poderá expandir-se a outros sistemas construtivos, tanto para sistemas estruturais completos como para subsistemas como telhados, fechamentos leves, paginações de brises, caixilhos, etc.
A utilização dos sarrafos e papelões, que são materiais facilmente manuseáveis, é a base para o estabelecimento de modulações estruturais variadas cujas dimensões são adaptadas a cada mock-up específico. A madeira apresenta a vantagem de poder ser serrada no local e a estrutura, aparafusada na hora, assume a forma determinada por cada projeto. Deste modo, com base em um sistema construtivo criado pelos professores no momento inaugural do curso (sistema que, por sua potencialidade didática, foi mantido e aperfeiçoado ao longo dos anos), as possibilidades de solução de projeto mostram-se bastante abertas e diversificadas. Neste aspecto, torna-se fundamental a participação do professor, na medida em que o canteiro se constitui uma oficina na qual o sistema pode ser continuamente aprimorado e o conhecimento gerado pode ser transmitido às novas turmas de alunos.

Cabe ainda ressaltar que o exercício, que considera inicialmente etapas de discussão e proposta conceitual e espacial, ao enfrentar o detalhamento e a construção, termina por agregar ao espaço um aspecto inerente ao campo disciplinar próprio da arquitetura, que diz respeito à sua materialidade. A experiência de desenvolver o projeto e realizá-lo com as próprias mãos, com rigor e precisão, seguida pela percepção do espaço real, contribui para selar a correspondência entre espaço e construção, e compreender o espaço como o vazio constituído a partir do limite da matéria, determinado por suas características físicas de modulação e superfície.

É preciso, neste momento, compreender a técnica não apenas como o conhecimento aplicado, evitando que a expressão arquitetônica se reduza a um rebatimento operativo do módulo estrutural. Neste sentido, no próprio ato do projeto, cabe pensar o sistema construtivo juntamente com a forma arquitetônica. Em outras palavras, os procedimentos e ações que ocorrem durante o ato de projeto devem conter a capacidade de vincular o desenho do espaço à materialidade e aproveitarem-se da interferência dinâmica e inventiva entre estes dois aspectos. Assim considerada, a técnica não é o mero recurso de materialização da forma, pensada a posteriori, e tampouco representaria uma limitação construtiva para um edifício idealizado de modo abstrato, mas apresenta-se fundida à própria capacidade de organizar o espaço. Pensar o espaço juntamente com seu sistema tectônico fortalece a solução formal do projeto de arquitetura enquanto solução que sintetiza a complexidade do problema dentro do campo disciplinar da arquitetura.

O enfrentamento do exercício tem, assim, possibilidade de despertar o aluno para esta relação, ampliando seu entendimento sobre a atividade do projeto e sua curiosidade sobre os aspectos construtivos nos edifícios, abrindo espaço para um olhar tectônico em sua formação. 
No que tange à execução, é preciso compreender que não se propõe o "aprender fazendo" como mera prática automática, mas como uma reflexão que vincula o projeto ao objeto real. O exercício se torna consequente na medida em que o problema colocado evidencia-se como próximo e concreto. O curto intervalo entre concepção e obra determina a possibilidade de estabelecer nexo e continuidade entre uma etapa e outra, verificar o impacto das decisões de projeto e interagir no processo através do próprio ato de fazer.

O curto intervalo entre concepção e obra auxilia ainda na compreensão da obra construída como um instrumento que retroalimenta as discussões dentro do campo da arquitetura, de modo a perceber a importância do domínio de um conjunto de soluções conhecidas como ponto de partida para a atividade de projeto.

Além do raciocínio construtivo, a proposta pedagógica do exercício permite a possibilidade de perceber o espaço em suas reais dimensões, transpondo o projeto de escala 1:20 para o tamanho real. Ao estabelecer a relação entre as maquetes 1:20 e 1:1, o estudante surpreende-se com o espaço, e passa a considerar a necessidade de imaginar o espaço real enquanto projeta, em vez de apenas manipular um desenho ou modelo abstrato em escala reduzida. A presença do corpo e o movimento no espaço, bem como as características de superfície do invólucro, tomam parte na experiência arquitetônica, uma vez que o estudante encontra-se posicionado dentro do espaço projetado durante todo o processo de construção. O projeto, por sua vez, deixa de ser apenas um dado abstrato e transfigura-se em um elemento real, entendido como algo que foi concebido e que contém em si os traços de todas as decisões tomadas ao longo do processo (figuras 10, $11 \mathrm{e}$ 12).

Os procedimentos de trabalho propiciados pelo exercício e o consequente desdobramento para a reflexão e prática, caracterizam uma situação propícia ao estabelecimento de uma pesquisa-ação, determinando um processo contínuo de aprimoramento das soluções e incorporação das experiências realizadas, possibilitando a reflexão sobre o conjunto de soluções que surgem ano a ano, a cada aplicação do exercício, redirecionando o problema espacial e possibilitando o aperfeiçoamento construtivo.

A perspectiva para tal pesquisa no futuro contempla dois caminhos. O primeiro diz respeito ao aprimoramento do exercício, com ênfase nos aspectos espacial e construtivo. Está previsto o levantamento e documentação dos cerca de 70 modelos construídos nos últimos quatro anos, para ser utilizado como material de referência.

O segundo caminho resvala na reflexão teórica acerca da relação entre prática e ensino, e no necessário aprofundamento de uma teoria da prática que possa rebater tanto em sala de aula como no canteiro, reflexão fundamental para conduzir a construção da autonomia do aluno em projeto.
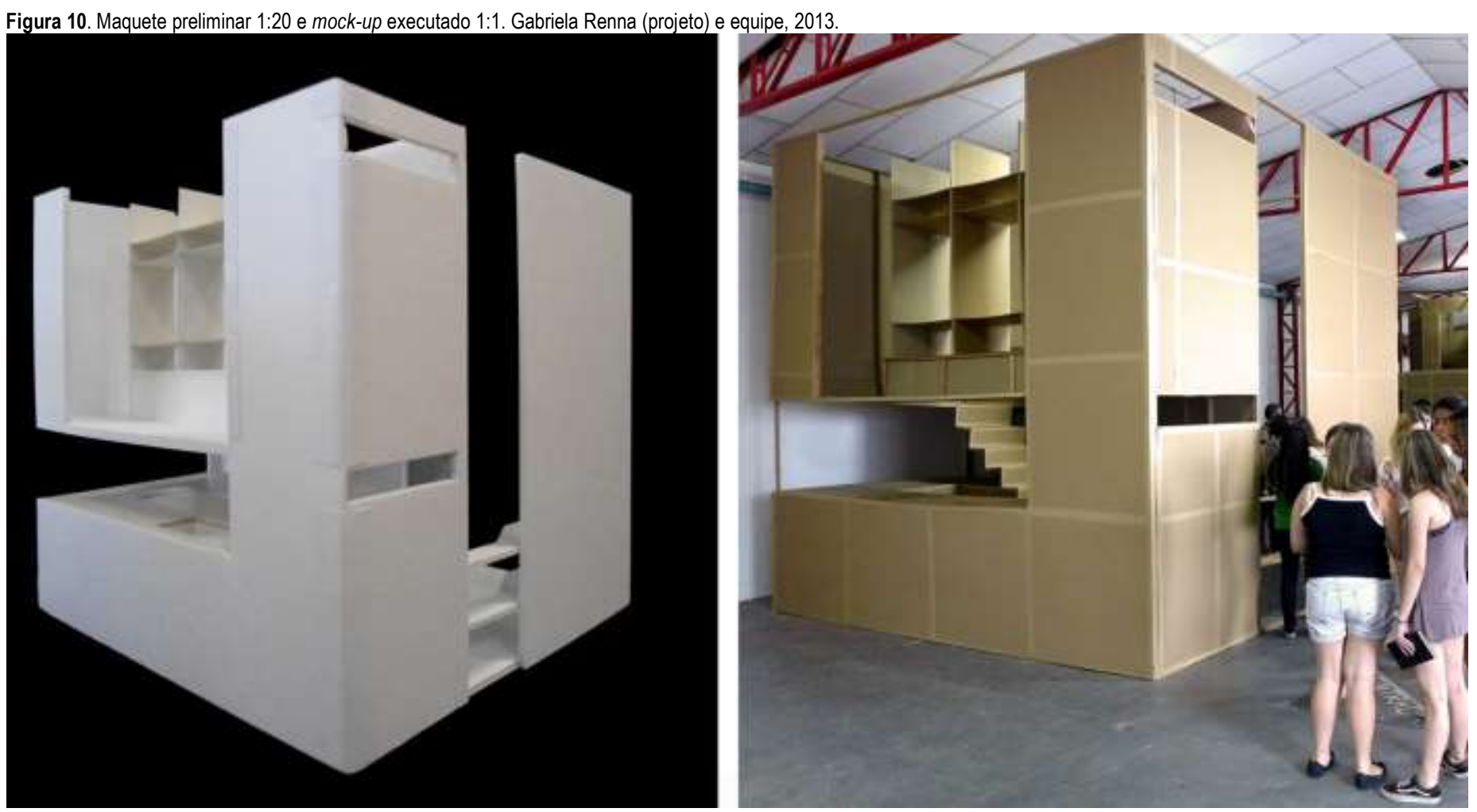

Fonte: Foto maquete: Gabriela Renna. Foto mock-up: do autor. 
Figura 11. Maquete preliminar 1:20 e mock-up executado 1:1. Matheus Lima Santos (projeto) e equipe, 2015.
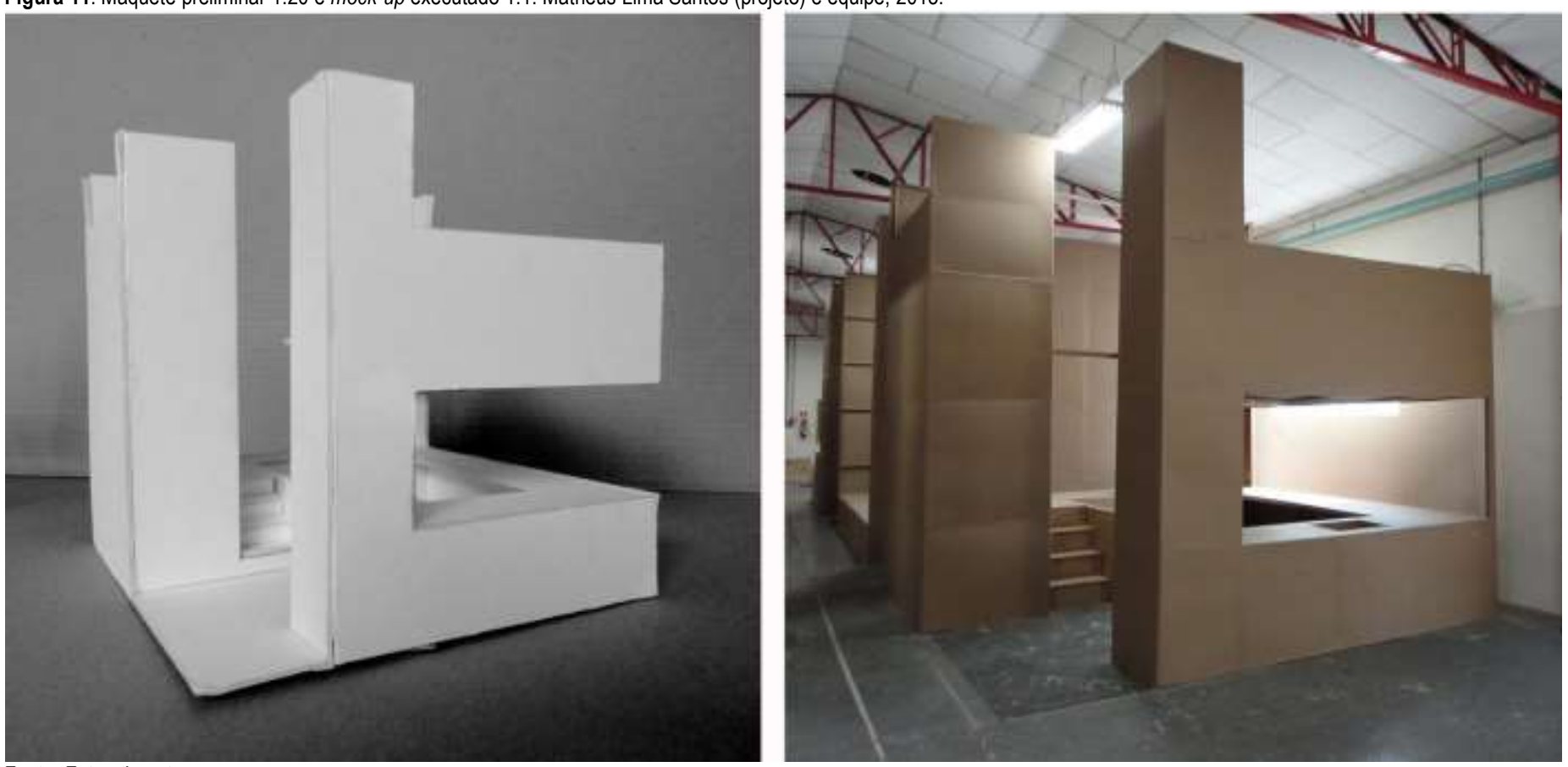

Fonte: Fotos do autor

Figura 12. Maquete preliminar 1:20 e mock-up executado 1:1. Leticia de Melo Barros (projeto) e equipe, 2015.
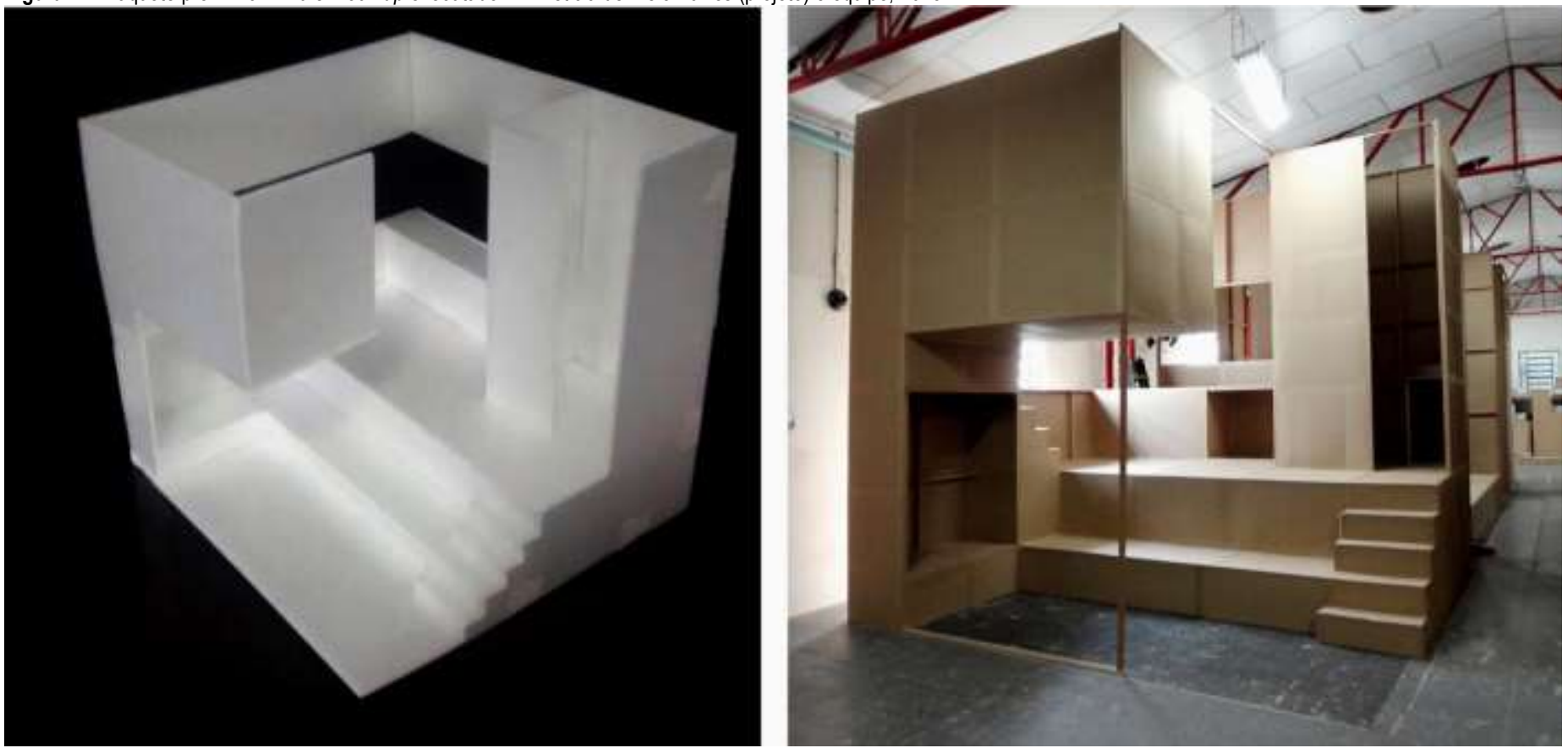

Fonte: Foto maquete: Letícia Barros; Foto mock-up: do autor

\section{Notas}

(1) Um artigo com mesmo tema foi apresentado no seminário VII PROJETAR 2015, em Natal, com o título Mock-up de Habitação 4X4X4m: primeiro exercício de projeto. O presente artigo constitui versão aprofundada daquele trabalho, e conta com ampliação do embasamento teórico; maior ênfase na relação entre o espaço e a tectônica; e reflexão sobre o ensino de Projeto de Arquitetura. 


\section{Referências}

DEPLAZES, A. Construir la arquitectura. Del material em bruto al edifício. Um manual. Barcelona: Gustavo Gili, 2010.

FRAMPTON, K. Studies in tectonic culture. Cambridge, MIT Press, 1995.

GREGOTTI, V. Território da arquitetura. São Paulo: Editora Perspectiva, 2004.

Contro la fine dell'architettura. Torino: Einaudi, 2008.

PIÑON, H. Teoria do projeto. Tradução de Edson Mahfuz. Porto Alegre: Livraria do arquiteto, 2006.

VELA, P. A. Entre la matéria y el espacio. Papel, cartón, encofrado. SUMMA +, Buenos Aires, n.67, p.137-139, julho 2004.

\section{${ }^{1}$ Maria Isabel Imbronito}

Arquiteta Urbanista. Doutora em Arquitetura e Urbanismo. Endereço postal: Rua Taquari, 546, São Paulo, SP, Brasil, CEP 03.166000 .

\section{${ }^{2}$ Eneida de Almeida}

Arquiteta Urbanista. Doutora em Arquitetura e Urbanismo. Endereço postal: Rua Taquari, 546, São Paulo, SP, Brasil, CEP 03.166000 . 